focus on German Studies.

https://journals.uc.edu/index.php/fogs

(ISSN 1076-5697)

Issue 27 (2020)

Book Review

\title{
Radio as Art: Concepts, Spaces, Practices
}

by Anne Thurmann-Jajes et al., VG Bild-Kunst, 2019. 312 pp. $\$ 48.99$

Bree'ya N. Brown

University of Texas at Austin

How to Cite: Brown, Bree'ya N. "Book Review: Radio as Art: Concepts, Spaces, Practices by Anne Thurmann-Jajes et al.". focus on German Studies 27: Spielformen des Authentischen, no. 27, 2020, pp. 101-106. doi: 10.34314/FOGS2020.000011. 


\section{Radio as Art: Concepts, Spaces, Practices}

\section{by Anne Thurmann-Jajes et al., VG Bild-Kunst, 2019. 312 pp. $\$ 48.99$}

Bree'ya N. Brown

Between 2011 and 2015, the Centre for Artists' Publication at the Weserburg Museum for Modern Art, the University of Bremen, and University of Cologne collaborated and conducted radio research projects. These projects explored ways artistic radio methods and practices produced in the early twentieth century have adapted to modern technologies and socio-political spheres. The central goal of the research was to bring accessibility to radio art and to audiences on a global scale. The project increased visibility of previously inaccessible radio broadcast archival materials through presentations in art exhibitions, survey exhibitions, and workshops. In June 2014, the three institutions' partnership produced an international symposium entitled, 'Radio as Art: Concepts, Spaces, Practices: Radio Art between Media Reality and Art Reception,' which resulted in the publication of Radio as Art: Concepts, Spaces, Practices. The monograph is sectioned into five parts - each of which includes a collection of essays - that examine acoustic phenomena, radio broadcasting, radio art discourse, and radio art from an artistic and historical perspective.

The introduction radiates the presence and impact of radio and art together. Jee-Hae Kim analyzes Robert Adrian Smith's significant role in art and art theory as a pioneer multidisciplinary media artist, by discussing the ways in which Smith structured his art projects about radio telecommunications. Telephone Music (1983), for example, connected countries together by telephone lines and Art \& Politics (1990-1994) grappled with memory and cultural politics after the fall of the Third Reich on the radio. Tetsuo Kogawa's work supports Kim's analysis, which contends that radio artists challenge the way transmissions are used as a power source to receive sounds in new ways. Hank Bull joins the conversation 
by arguing that from the time of its conception, electricity continues to act as a constant concept, medium, and tool for art. Bull manages to simultaneously interweave and untangle human adaptation to electricity demonstrated in fiction novels, paintings, performances, and theoretical frameworks.

Thinking about radio broadcasting as an art medium, the first section "Radio Space," introduces the impact of radio broadcasting in public and private spheres. Sarah Rothe and Colin Black both discuss the significance of radio art in traditional exhibition environments that normally draw large crowds. In her essay, Rothe surveys collaborative projects between museums and radio artists, revealing the agency of both forces. The partnership further results in the communication of art, raises individuals' perceptions of self-awareness, and engages participants in conversation. Whereas Rothe focuses on qualitative and quantitative sources to analyze the experiences, Black applies transportation theories of communication and a post-structural theory to explain ways that individuals perceive art forms through different mediums, symbolic forms, sounds, and audio production. Andreas Zeisung addresses the Novembergruppe's social agenda, positing evening radio programs as a rich avant-garde cultural experience for Berliners, despite being under nation-state control during the Weimar Republic. Together, the authors assemble a captivating elucidation and unveil the ways production of radio art and act of receiving it through audio formats is a form of agency.

In "Radio Art: Artistic Production and/or Political Practice," Philip Glahn, Claudia Wagner, Franziska Rauh, and Ursula Frohne examine events in which the radio was used as a tool for political activism while under the scrutiny of governments. Glahn expresses, with great apprehension, that the daily consumption of social media and the advancement of smartphones brought about the death of the radio movement. Wegener and Rauh broaden the conversation to address the limitations of radio transmission in marginalized societies. 
Wegner discusses the emergence of a DURBAN SINGS audio media and oral history (2008). In order to broadcast radio programs and stream videos online, the South African government requires broadcasters to obtain and maintain air-community licenses. Despite the broadcasting limitations, producers found exposure through DVD and CD format and social media. Rauh focuses on Oda Projesi (2000), a radio project created by a collective of women artists in Istanbul, Turkey, highlighting power relations, collective organization, dissent, and alternative counter-public media. Lastly, Frohne's essay provides further reassurance that radio remains a symbolic medium and critical tool utilized by marginalized communities. With the emergence of radio projects after the 1968 movements in Europe like the Czechoslovak Radio 1968 and the Babel tower of radios, minor art forced hegemonic collectives among citizens and challenged traditional major art and agitprop.

In an effort to support the argument that radio art and broadcasting are interdisciplinary, the third section on "Institutional Framing Agency," features essays dedicated to understanding oral histories as an artistic framework. Sibylle Omlin insists that artists should pursue investigative research, similar to that of journalist methods, in order to document and circulate oral histories. To combat common skepticism surrounding oral history methodologies, Omlin argues that artists who use an oral history approach expose details that cannot be heard if using another type of approach. Sarah Washington's article emphasizes Omlin's arguments, by discussing analogue broadcasting in different countries. The article showcases the ways radio independently gained certain privileges, while living in politically strict environments. Washington contends that community radio contributes to the development of a landscape where art and representation can thrive together. Natalie Singer argues that the discourse on radio art orbits around the realities of the inaccessibility of art and the lack of academic teaching and research on radio art. Andreas Hagelüken further supports previous points made in this section, concluding the use of oral history 
methodology combined with broadcasting as another form of art and journalism. With this in mind, Singer and Hagelüken indulge the idea that accessibility of radio art advances technique and pedagogy, further recognizing radio art as an interdisciplinary field.

Focusing on the perception of radio communication by listeners, scholars hone in on conversations centered around artistic aspects presented through exhibits, collaborative art projects, and broadcastings. In the fourth section entitled "Radio Art as Action," Roksana Filipowska narrates the invention of the transistor radio that emerged in 1960s Britain. This technological invention along with the "Archigram" (191)- which emerged as an architectural practice for collaborative artworks - and pirate radio stations, like Radio Carroline and Radio London, surfaced and developed the age of consciousness. Kai van Eikels focuses on radio concepts in context to participation. Referencing LIGNA's Oedipus Rex (live radio ballet performance based in Hamburg), Eikels dives into the connections between radio airwaves, the physical, consciousness, and the individual experience as a process to understand the collective experience in 1960s Great Britain. Irina Gheorghe underlines both Filipowska and Eikels'analyses by dissecting pro-life Orthodox views on radio programs broadcasted under dictatorship in 1980s Bucharest, Romania.

The collection of essays presented in the fifth section, "Words-Sounds-Music," consider the act of engaging with radio art primarily through sound. Lauren Rosati utilizes a cinematic perspective to discuss John Cage's pioneering composition of electroacoustic sounds that transformed mediums of cinema and radio through films and speakers. Employing Peter Roehr's artistic photomontage and sound montages, in her article Nadine Hahn analyzes the ways Roehr's works transformed visual formats, like Volkswagen radio advertisements. Hahn's assumptions are highlighted by Ania Mauruschat's historical examination of German Hörspiel (radio play) between the mid 1920s and 1990s, and Vito Pinto's analysis on Paul Plamper's Hörspielmacher. Both Mauruschat and Pinto intersect in 
conversation identifying the ways sounds evoke themes and aesthetic impact. Anne Thurmann-Jaje concludes this section to elaborate on the radio art discourse. From an art historical framework, radio art constitutes nonvisual, immaterial, placeless, intermedial, timebased, and disseminated structures formed by technique and media.

The essays presented in the book could have further examined the production and influence of radio art and radio transmission with regard to marginalized communities and grass-root projects that emerged in the twentieth and twenty-first centuries. This approach would not only uncover compelling stories, but it could also assist readers in understanding the complexities of creating, developing, practicing, and accessing radio art. The contributions, nevertheless, made to Radio as Art fill in the small gaps in art scholarship that overlook concepts, practices, and debates that frame radio broadcast, sounds, and transmission as an artistic approach. As society progresses further into the contemporary information age of social media, technology, and digital communications, academics should continue to inquire and understand ways in which critical discourses from the past exhibit various connections to the present day and what may benefit the progression of radio art. 